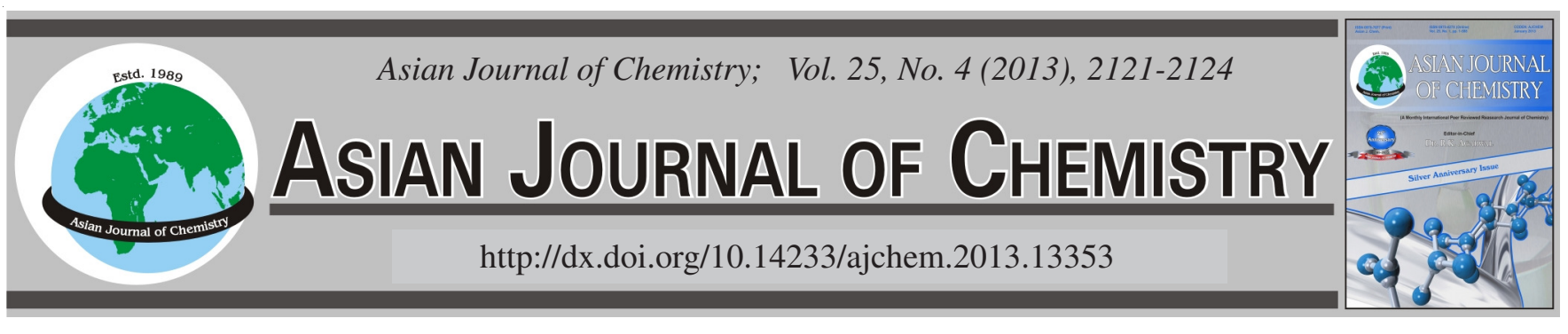

\title{
Syntheses and Characterization of Alkyl-pectin Materials
}

\author{
X.F. ZHENG ${ }^{1, *}$, Q. $\operatorname{LIAN}^{1}$, H. YANG ${ }^{2}$, D.D. JIA ${ }^{1}$ and D.J. $\mathrm{WANG}^{1}$
}

${ }^{1}$ School of Physics and Chemistry, Hebei Normal University of Science and Technology, Qinhuangdao 066600, P.R. China

${ }^{2}$ Chemistry and Chemical Engineering School, Guangxi University, Nanning 530004, P.R. China

*Corresponding author: Tel: +86 24 2039067; E-mail: xuefang-zheng@163.com

(Received: 29 December 2011;

Accepted: 17 October 2012)

AJC-12294

The present study is related to develop novel colon specific drug delivery systems using chitosan and pectin as a microbially degradable
polymeric carrier. Alkyl-pectin with various degrees of substitution were prepared by heterogeneous alkylation of pectin with alkyl
bromide. The results showed that the alkyl-pectin with insolubility can be obtained based on the optimal reaction condition. The ratio of
pectin to 1-bromoctane mole number was $1: 9$, reaction time is $8 \mathrm{~h}$ with temperature of $80^{\circ} \mathrm{C}$ and the weight ratio of tetrabutyl ammonium
bromide to pectin is $0.5 \%$. The alkyl-pectin structure were characterized by FT-IR Elemental analyses, differential scanning calorimetry
analysis and ${ }^{1} \mathrm{H}$ NMR analysis. The findings of the present study conclusively state that alkyl-pectin are promising for colon targeting of
drugs.

Key Words: Pectin, Alkylate, Alkyl bromide, Degrees of substitution, Hydrophobicity.

\section{INTRODUCTION}

Interest in polymeric matrices for pharmaceutical formulation continues to grow. Special attention is currently given to pectin. Pectin carboxyl groups are reactive at higher $\mathrm{pH}$ values. They are a suitable site for chemical modifications and for enzyme immobilization ${ }^{1}$. Since pectin itself is nontoxic ${ }^{2}$, biodegradable $^{3}$ and biocompatible ${ }^{4}$, several biological applications have been reported for pectin, including site-specific drug delivery systems ${ }^{5,6}$ and a drug carrier ${ }^{7}$. Pectin has been modified by cross-linking (e.g. glutaraldehyde) to prepare polyion-complex hydrogels ${ }^{8}$.

Pectin has been described as drug carrier for colonspecific drug delivery ${ }^{9-11}$. Pectin has good swelling behaviours, drugs with high solubility display a pre-mature release due to the expanded pore size of pectin formulations. In order to decrease swelling ability, pectin derivatives with hydrophobic residues were prepared. $N$-octadecylpectinamide is an example with non-polar side chains ${ }^{12}$, the hydrophobic relationship of such polymers depends on the degree of substitution ${ }^{13}$. Chemical structure of pectin is as follows:

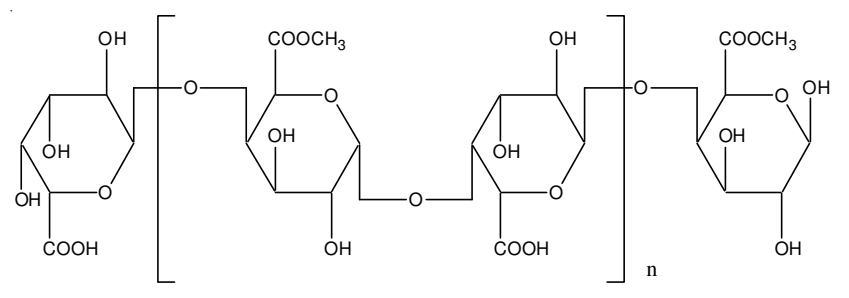

In the paper, various substituted pectin with alkyl groups were prepared and characterization by spectroscopic and other methods. The present study describes the alkyl-pectin with alkyl bromide to introduce hydrophobicity for use as matrix for drug delivery. It was expected that such derivatization would reduce hydration of the matrix and play a role in network stabilization by hydrophobic interactions. The pectin derivatives were examined by Fourier-transform infrared, proton nuclear magnetic resonance spectroscopy, differential scanning calorimetry analysis and elemental analyzer.

\section{EXPERIMENTAL}

Pectin was purchased from Fuda Pectin Chemical Co., in China. Its degree of methylation was $70 \%$ determined by elemental analysis. 1-bromoctane, 1-bromododecane and 1-bromohexdecane were purchased from Aldrich Chemical Co. Inc., all commercially solvents and reagents were used without further purification. All other chemicals were of analytical grade.

Preparation of alkyl-pectin: $\mathrm{N}$-alkylation of pectin was carried out using alkyl bromide in a heterogeneous system in isopropyl alcohol. $1 \mathrm{~g}$ of pectin was dispersed in $25 \mathrm{~mL}$ isopropyl alcohol under stirring, addition of $1 \mathrm{~g} \mathrm{NaOH}$ provided the required alkaline environment and cooled at $-18{ }^{\circ} \mathrm{C}$ for $24 \mathrm{~h}$. The mixtures were added water $15 \mathrm{~mL}$ after solved at $25^{\circ} \mathrm{C}$, tetrabutyl ammonium bromide as catalyst was added and kept $0.5 \%$. The alkylation started by adding alkyl bromide 
to the solution, the reaction was carried out under continuous mixing at $80^{\circ} \mathrm{C}$. The products were precipitated using a mixture of ethanol and ether $(1: 1)$, filtered and thoroughly washed with hexane and acetone. The precipitate, collected by filtration, was washed with an excess of hexane and decanted. The washing was repeated three times to eliminate free reagents. Finally, the products were dried with pure acetone to obtain the corresponding derivative powders.

Solubility assay: $10 \mathrm{mg}$ of the pectin derivatives was taken in a small beaker and wetted with a drop of ethanol. Then 10 $\mathrm{mL}$ sample was added into various solutions. The mixture was stirred on a magnetic stirrer for $1 \mathrm{~h}$ and filtered on paper filters. The filters with residual solids were dried and weighted for the estimation of non-soluble solids. The samples were defined as well soluble, partially soluble (markedly lower amount of solids) and insoluble (less than $5 \%$ ).

Molecular structure: The main aspects were examined in this study: the effect of alkyl chains length (Scheme-I) and the degree of substation on the structure and behaviour of pectin.

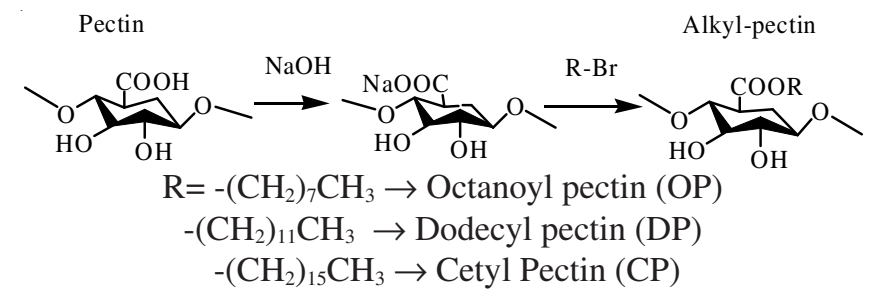

Scheme-I: Pectin derivatization with alkyl bromides

Fourier-transform infrared analysis: Fourier-transform infrared spectra were recorded using a spectrum one spectrophotometer (NICOLET 200SXV FT-IR, Perkin Elmer, USA) equipped with an Universal Attenuated Total reflectance (UATR) device for tablet analysis in the spectral region (4500$500 \mathrm{~cm}^{-1}$ ) with 64 scans recorded at a $4 \mathrm{~cm}^{-1}$ resolution.

Differential scanning calorimetry analysis: Thermal properties were measured by differential scanning calorimetry analysis, using a differential scanning calorimetry 823 (Mettler Toledo, Columbus, $\mathrm{OH}$ ) with a quench-cooling accessory. Aliquots of approximately $10 \mathrm{mg}$ samples previously conditioned $\left(23^{\circ} \mathrm{C}, 50 \%\right.$ relative humidity for 2 weeks $)$ were placed in hermetically-sealed aluminium pans to prevent moisture loss during analyses and then heated at $10{ }^{\circ} \mathrm{C} \mathrm{min}{ }^{-1}$ from $5{ }^{\circ} \mathrm{C}$ to $110^{\circ} \mathrm{C}$ in an inert environment $\left(100 \mathrm{~mL} \mathrm{~min}^{-1} \mathrm{~N}_{2}\right)$. The first scan was immediately followed by quick cooling to $5^{\circ} \mathrm{C}$ at a rate of $40{ }^{\circ} \mathrm{C} \mathrm{min}{ }^{-1}$ using liquid nitrogen and the second scan was then run. Before taking the measurements, the instrument was calibrated with an indium standard. The glass transition temperature $\left(\mathrm{T}_{\mathrm{g}}\right)$ of all the samples was determined as the point of inflexion in the base line (second scan) caused by the discontinuity of specific heat capacity of the sample. The helix-coil transition temperature, $\mathrm{T}_{\mathrm{m}}$ also called interchangeable melting or denaturation temperature ${ }^{14}$, was measured as the temperature of the endothermic peak (fist scan). The value of helix-coil transition enthalpy $(\Delta \mathrm{H})$ was assumed derived from the amount of renaturated pectin and was normalized to the sample weight determined immediately before each measure- ment. $T_{g}, T_{m}$ and $\Delta H$ were calculated by the software STAR version 9.0 .

${ }^{1}$ H NMR (proton nuclear magnetic resonance): Highresolution ${ }^{1} \mathrm{H}$ NMR spectra were recorded on a Varian Unity INOVA-400 spectrometer. Samples were prepared as described by Heus et al. ${ }^{15}$. Native or modified pectin were dissolved at a concentration of $2 \%$ in deuterated water with $\mathrm{CH}_{3} \mathrm{COOD}$. These solutions were then freezed / defreezed three times to exchange labile proton with deuterium and their spctra were recorded at $330 \mathrm{~K}$.

\section{RESULTS AND DISCUSSION}

In alkyl substitution reaction, the main factors of influence the substitution degree are: the activity of bromination, mass of the catalyzer, basification concentration, length of the alkyl, etc. All kinds of reaction conditions on the influence of alkylpectin, in bromooctane as a benchmark.

Effect of basification concentration: Table-1 shows the effect of basification concentration on octyl-pectin. Alkyl pectin is soluble with $\mathrm{NaOH}$ concentration of $0.25 \%$, when $\mathrm{NaOH}$ concentration increases to $0.5 \%$, alkylation pectin presents hydrophobic. However, when $\mathrm{NaOH}$ dosage is higher than $0.5 \%$, the system will occur some side-reactions, such as pectin oxidation, deacetylation, degradation, etc., which shows that the high dosage of $\mathrm{NaOH}$ is unfavourable. Therefore, with octyl pectin soluble in water as the basis, the optimal concentration $\mathrm{NaOH}$ is $0.5 \%$.

\begin{tabular}{ccc} 
& \multicolumn{2}{c}{ TABLE-1 } \\
& \multicolumn{2}{c}{$\begin{array}{c}\text { EFFECT OF BASIFICATION CONCENTRATION } \\
\text { ON OCTYL-PECTIN }\end{array}$} \\
\hline Sample & NaOH concentration $(\%)$ & Solubility \\
\hline 1 & 0.25 & Partially soluble \\
2 & 0.50 & Hydrophobic \\
3 & 0.75 & Hydrophobic \\
\hline Pectin: $\mathrm{C}_{8} \mathrm{H}_{17} \mathrm{Br}(\mathrm{mol}:$ mol $) ~ 1: 9$, tetrabutyl amonium bromide $0.2 \mathrm{~g}$, \\
isopropanol $40 \mathrm{~mL}$, time $8 \mathrm{~h}$, temperature $80^{\circ} \mathrm{C}$ &
\end{tabular}

Effect of catalyst dose and type on octyl pectin: Table- 2 shows the effect of catalyst dose and type on octyl pectin. The catalytic effect is best with tetrabutyl amonium bromide (TBAB ) for phase transfer catalyst and alkyl pectin is hydrophobic. According to the principle of phase transfer catalyst of starks, catalytic activity can be concluded that the activity of catalyzer depends on the carbon and symmetry of catalyzer. The more carbon, the better the symmetry of phase transfer catalysts, the better $\mathrm{HBr}$ or $-\mathrm{Br}$ transferred to the ability of organic phase, catalytic activity is better.

TABLE-2

EFFECT OF CATALYST DOSE AND TYPE ON OCTYL PECTIN

\begin{tabular}{clcc}
\hline Sample & Catalysator & $\begin{array}{c}\text { Catalyst } \\
\text { amount }\end{array}$ & Solubility \\
\hline 1 & None & - & Hydrophillic \\
2 & Tetramethylammonium hydroxide & $2 \mathrm{~mL}$ & Hydrophillic \\
3 & Tetrabutyl amonium bromide & $0.1 \mathrm{~g}$ & Hydrophillic \\
4 & Tetrabutyl amonium bromide & $0.2 \mathrm{~g}$ & Hydrophobic \\
\hline
\end{tabular}

Pectin: $\mathrm{C}_{8} \mathrm{H}_{17} \mathrm{Br}$ (mol: mol) 1:9, $\mathrm{NaOH}$ concentration $0.5 \%$, isopropanol $40 \mathrm{~mL}$, time $8 \mathrm{~h}$, temperature $80^{\circ} \mathrm{C}$ 
Effect of the ratio of pectin: alkyl bromide: Table- 3 showed degree of substitution and solubility of alkyl-pectin. The degree of substitution of alkyl groups was from 0.04 to 0.14 due to the difference of amount and kinds of 1-bromoctane. The degree of substitution of alkyl groups was reduced with increasing the alkyl chain length and decreasing the amount of 1-bromoctane. These results clearly demonstrated that the degree of substitution of the products was strongly controlled by the activity of alkyl bromide.

\begin{tabular}{|c|c|c|c|c|c|}
\hline \multicolumn{6}{|c|}{$\begin{array}{c}\text { TABLE-3 } \\
\text { DEGREE OF SUBSTITUTION (DS) AND } \\
\text { SOLUBILITY OF ALKYL-PECTIN }\end{array}$} \\
\hline \multirow[b]{2}{*}{ Sample } & \multirow{2}{*}{$\begin{array}{l}\text { Pectin: alkyl } \\
\text { bromide } \\
(\mathrm{mol} / \mathrm{mol})\end{array}$} & \multirow[b]{2}{*}{ DS } & \multirow{2}{*}{$\begin{array}{c}\text { Analysis } \\
\text { conclusion } \\
\mathrm{C}(\%)\end{array}$} & \multicolumn{2}{|c|}{ Solubility } \\
\hline & & & & Water & $\begin{array}{c}0.05 \mathrm{~mol} \mathrm{l}^{-1} \\
\mathrm{NaOH}\end{array}$ \\
\hline 1 & $1: 2\left(\mathrm{C}_{8} \mathrm{H}_{17} \mathrm{Br}\right)$ & 0.0706 & 30.083 & Soluble & Soluble \\
\hline 2 & $1: 6\left(\mathrm{C}_{8} \mathrm{H}_{17} \mathrm{Br}\right)$ & 0.1360 & 31.157 & $\begin{array}{c}\text { Partially } \\
\text { soluble }\end{array}$ & Soluble \\
\hline 3 & 1:9( $\left.\mathrm{C}_{8} \mathrm{H}_{17} \mathrm{Br}\right)$ & 0.1412 & 32.428 & Insoluble & Swelling \\
\hline 2 & $1: 9\left(\mathrm{C}_{12} \mathrm{H}_{25} \mathrm{Br}\right)$ & 0.06538 & 29.366 & Insoluble & Swelling \\
\hline 3 & $1: 9\left(\mathrm{C}_{16} \mathrm{H}_{33} \mathrm{Br}\right)$ & 0.04905 & 31.273 & Insoluble & Swelling \\
\hline
\end{tabular}

Solubility: Substitution caused a gradual loss of its hydrophilic properties (Table-1), such as $\mathrm{C}_{8} \mathrm{H}_{17}$-pectin, when degree of substitution $=0.07$, polymer was soluble in water at small degrees of substitution; when $0.07<\mathrm{DS}<0.13$, the polymers were first swelling, then partly soluble, it have surface-active properties and can interact with lipid bilayers and globularproteins ${ }^{16}$. When DS $>0.14$, alkyl groups leads to insolubility in water. With increasing the alkyl chain length, insoluble alkyl-pectin required less substitution, for example, when alkyl-pectin began to be insoluble in water, the DS of $\mathrm{C}_{8} \mathrm{H}_{17}$-pectin, $\mathrm{C}_{12} \mathrm{H}_{25}$-pectin and $\mathrm{C}_{16} \mathrm{H}_{33}$-pectin were 0.04905 , 0.06938 and 0.1412 .

In alkali conditions $\left(0.05 \mathrm{~mol} \mathrm{~L}^{-1} \mathrm{NaOH}\right)$ the solubility of alkyl-pectin markedly increased owing to ionization of free carboxyls and some degradation of polysaccharide molecules via elimination. The insoluble alkyl-pectin had swelling behaviour.

FT-IR analysis: After alkylation, the vibrational band corresponding to primary carboxyl groups at $1600 \mathrm{~cm}^{-1}$ disappeared (Fig. 1), while prominent bands at $1740 \mathrm{~cm}^{-1}$ were observed. The absorption peaks at $2930-2850 \mathrm{~cm}^{-1}$ were ascribed $-\mathrm{CH}_{2}$; their intensity was proportional to the alkyl chain length. These results clearly confirmed that the pectin was substituted.

Thermal properties: Thermal properties were measured by DSC. The glass transition temperature $\left(\mathrm{T}_{\mathrm{g}}\right)$ of pectin was gradually altered with the increasing alkyl pectin length (Fig. 2). The DSC of pectin showed peaks of moderately low intensity and broader than those of dodecyl pectin (DP) and cetyl pectin (CP). In case of octanoyl pectin (OP) (short chain), the glass temperature showed only a diffuse peak (at $210.59^{\circ} \mathrm{C}$ ), higher than that of pectin. With longer alkyl chains length $\left(\mathrm{C}_{8}-\mathrm{C}_{16}\right)$, the glass temperature peaks became higher; moreover, the peak areas became broader. These major changes suggested a more stable organization than for other forms of pectin.

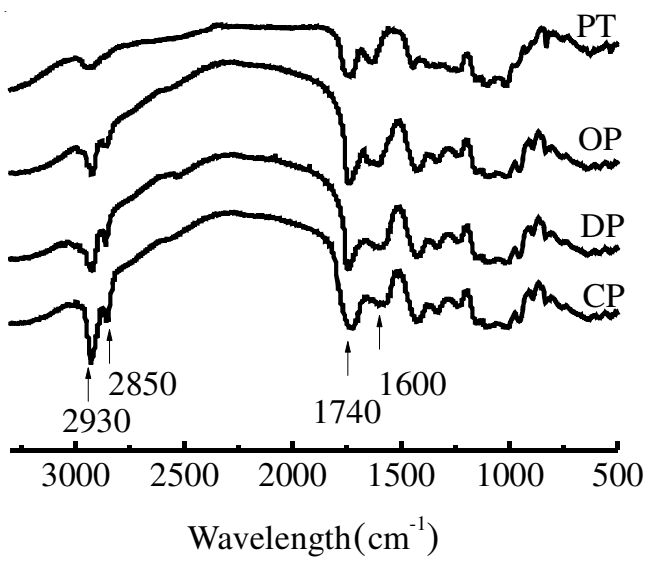

Fig. 1. FT-IR spectra of pectin and alkyl-pectin

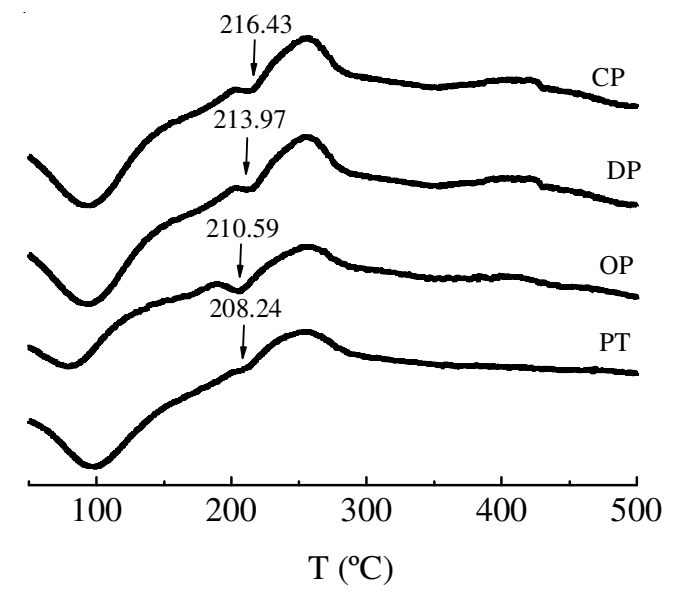

Fig. 2. DSC of the alkyl pectin

Furthermore, it seems that these hydrophobic interactions can enhance the stability and participate in a self-assembled network organization.

${ }^{1} \mathbf{H}$ Nuclear magnetic resonance: In order to further confirm the formation of the alkyl-pectin, the ${ }^{1} \mathrm{H}$ NMR spectra were measured. ${ }^{1} \mathrm{H}$ NMR spectra of the alkyl-pectin was shown in Fig. 3. The important signals at $0.9 \mathrm{ppm}$ and $1.1 \mathrm{ppm}$ were assigned to the protons of $\mathrm{C}-\mathrm{H}$ and $\mathrm{CH}_{3}$ of the alkyl groups. The other signals at 3.1-4.4 ppm were assigned to interaction of pectin.

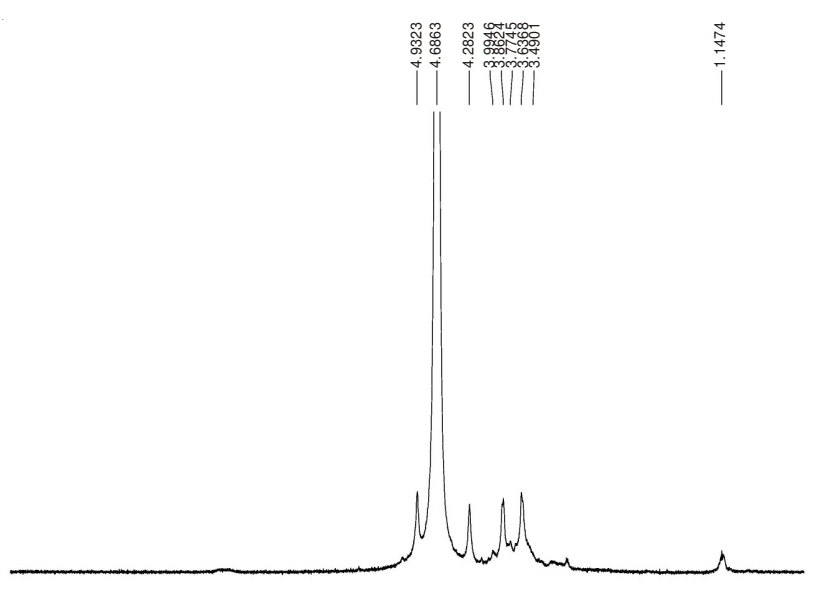

$\begin{array}{llllllllllllllllllll}9.5 & 9.0 & 8.5 & 8.0 & 7.5 & 7.0 & 6.5 & 6.0 & 5.5 & 5.0 & 4.5 & 4.0 & 3.5 & 3.0 & 2.5 & 2.0 & 1.5 & 1.0 & \mathrm{ppm}\end{array}$

Fig. 3. ${ }^{1} \mathrm{H}$ NMR spectrum of octyl pectin 


\section{Conclusion}

The optimal conditions in synthesis of alkyl pectin using pectin and alkyl bromide as raw materials are: the ratio pectin to bromoisooctane mol number is $1: 9$, the mass concentration of $\mathrm{NaOH}$ is $0.5 \%$, the volume of isopropanol is $40 \mathrm{~mL}$, reaction temperature is $80^{\circ} \mathrm{C}$, the reaction time is $8 \mathrm{~h}$. The alkyl-pectin structure were characterized by FT-IR, elemental analyses, differential scanning calorimetry analysis and ${ }^{1} \mathrm{H}$ NMR analysis. Alkyl-pectin was an example of hydrophobically modified pectin that could be used in various applications. An introduction of alkyl groups into pectin macromolecules has led to significant changes of physical and chemical properties of pectin, first of all to increasing of its hydrophobicity. The hydrophobic ability of alkyl pectin may be improved by increasing of substitution degree and (or) by increasing length of alkyl chain.

\section{ACKNOWLEDGEMENTS}

This work was supported by Financial support from Hebei fund committee under contract No. B2008000465 and students studying abroad technology outstanding project of Hebei Province (No. HB20070036). The authors thank Prof. Hua Yang, Guangxi University, for the contribution to the manuscript.

\section{REFERENCES}

1. R. Semdé, K. Amighi, M.J. Devleeschouwer and A.J. Moës, Int. J. Pharm., 197, 169 (2000).

2. D.N. Venkatesh, A.K. Reddy, M.K. Samanta and B. Suresh, Asian. J. Pharm., 3, 50 (2009).

3. T. Katav, L.S. Liu, T. Traitel, R. Goldbrt, M. Wolfson and J. Kost, J. Control. Rel., 130, 183 (2008).

4. O. Chambin, G. Dupuis, D. Champion, A. Voilley and Y. Pourcelot, Int. J. Pharm., 321, 86 (2006).

5. V. Pillay and R. Fassihi, J. Control. Rel., 59, 229 (1999).

6. M. Turkoglu and T. Ugurlu, Eur. J. Pharm. Biopharm., 53, 65 (2002).

7. M. Sadeghi and J. Biomate, Nanobiotechnol., 2, 36 (2011).

8. S. Farris, K.M. Schaich, L.S. Liu, P.H. Cooke, L. Piergiovanni and K.L. Yam, Food Hydrocol., 25, 61( 2011).

9. V.R. Sinha and R. Kumria, Int. J. Pharm., 224, 19 (2001).

10. O. Munjeri, J.H. Collett and J.T. Fell, J. Control. Rel., 46, 273 (1997).

11. G.S. Macleod, J.H. Collett and J.T. Fell, J. Control. Rel., 58, 303 (1999).

12. C. Tribet, Biochimie, 80, 461(1998).

13. A. Synytsya, J. Copikova, M. Marounek, P. Mlcochová, L. Sihelníková, S. Skoblya, H. Havlátová, P. Matejka, M. Maryška and V. Machovic, Carbohydr. Polym., 56, 169 (2004).

14. I.S. Arvanitoyannis, A. Nakayama and S.I. Aiba, Carbohyd. Polym., 37, 371 (1998).

15. L. Heux, J. Brugnerotto, J. Desbrières, M.F. Versali and M. Rinaudo, Biomacromolecules, 1, 746 (2000).

16. C.L. Tien, M. Lacroix, P. Ispas-Szabo and M.A. Mateescu, J. Control. Rel., 93, 1 (2003). 